\title{
渦中心軸方向流速の分布を有する渦モデルの開発と検証
}

\author{
伊藤 啓 ${ }^{* 1}$ ，江連 俊樹 ${ }^{* 1}$ ，大島 宏之 ${ }^{* 1}$
}

\section{Development of vortex model with realistic axial velocity distribution}

\author{
Kei ITO*1 ${ }^{* 1}$ Toshiki EZURE ${ }^{* 1}$ and Hiroyuki OHSHIMA ${ }^{* 1}$ \\ ${ }^{1}$ Japan Atomic Energy Agency \\ 4002 Narita-cho, Oarai-machi, Higashiibaraki-gun, Ibaraki 311-1393, Japan
}

\section{Received 3 June 2014}

\begin{abstract}
A vortex is considered as one of significant phenomena which may cause gas entrainment (GE) and/or vortex cavitation in sodium-cooled fast reactors. In our past studies, the vortex is assumed to be approximated by the well-known Burgers vortex model. However, the Burgers vortex model has a simple but unreal assumption that the axial velocity component is horizontally constant, while in real the free surface vortex has the axial velocity distribution which shows large gradient in radial direction near the vortex center. In this study, a new vortex model with realistic axial velocity distribution is proposed. This model is derived from the steady axisymmetric Navier-Stokes equation as well as the Burgers vortex model, but the realistic axial velocity distribution in radial direction is considered, which is defined to be zero at the vortex center and to approach asymptotically to zero at infinity. As the verification, the new vortex model is applied to the evaluation of a simple vortex experiment, and shows good agreements with the experimental data in terms of the circumferential velocity distribution and the free surface shape. In addition, it is confirmed that the Burgers vortex model fails to calculate accurate velocity distribution with the assumption of uniform axial velocity. However, the calculation accuracy of the Burgers vortex model can be enhanced close to that of the new vortex model in consideration of the effective axial velocity which is calculated as the average value only in the vicinity of the vortex center.
\end{abstract}

Key words : Vortex model, Axial velocity, Gas entrainment, Gas core, Surface tension, Fast reactor

\section{1. 緒言}

様々な流体機械において観察される渦流れは，流れ場中の抵抗要素となるだけでなく，振動・騒音といった現 象の原因となり得るため，渦流れによって誘起されるこれらの現象について，その影響を正確に評価することは 重要である. 日本原子力研究開発機構（以下，機構）においても，ナトリウム（Na）冷却高速炉（JSFR）の安全 設計指針構築のため, 渦流れによって誘起され得る現象（自由界面におけるガス巻込み，液中渦キャビテーショ ン）の評価手法開発を実施している(大島他，2012a，2012b). 本評価手法では，従来のようにスケール試験に基 づく評価ではなく，実機を模擬した CFD 結果から得られる局所量（循環，下降流速勾配等）と渦モデルを用いて ガス巻込みや夜中渦キャビテーションの発生判定を行う。現在では，渦中心軸方向流速に対して一様分布を仮定 した Burgers 渦モデル(Burgers, 1948)を採用しているが，実際の渦流れにおいては渦中心軸方向流速の分布が存在 するため, Burgers 渦モデルを用いることの妥当性については必ずしも明らかになっていない.

渦中心軸方向流速の分布を考慮した渦モデルとしては, Sullivan モデル(Sullivan, 1959)や Einstein モデル(Einstein and Li, 1951)が有名である．前者は竜巻のモデルとして良く用いられる 2 セル構造の渦モデルであり，JSFR にお いて問題としている渦とは大きく異なる流速分布を与える。また，後者は渦中心近傍のみに一様な渦中心軸方向 流速を与える渦モデルであり，非常に単純化された流速分布を用いているために実際に観察される渦の流速分布 の再現性は低い. その他の渦モデルとしては, Bohling らが連続的な渦中心軸方向流速の分布を持つモデルを提案

\footnotetext{
No. 14-00296 [DOI: 10.1299/transjsme.2014fe0299]

*1 正員，(独）日本原子力研究開発機構（干311-1393 茨城県東茨城郡大洗町成田町 4002）

E-mail of corresponding author: ito.kei@jaea.go.jp
} 
している(Bohling, et al., 2010). しかし，Bohling らのモデルは渦中心近傍における流速分布（染料コアと呼ばれる 低流速領域の存在）を表すことができないため，流速分布の再現性は十分ではない．

本研究では，実現象（計測結果）に即した渦中心軸方向流速の分布を有する渦モデルの開発を行い，実際の渦 流れにおける流速分布等を再現できることを示す．また，開発する渦モデルを用いた計算結果と従来手法（改良 した Burgers 渦モデル）による計算結果を比較検討することにより，渦モデルの現象再現性に関する検討を行う.

\section{Burgers 渦モデルに基づく評価手法の概要}

ここでは，単純化のために軸対称の渦流れを考える．この場合，渦流れは，以下の軸対称 Navier-Stokes 方程式 $(r-\theta-z$ 方向 $)$ によって記述される.

$$
\begin{aligned}
& \frac{1}{r} \frac{\partial r u_{r}}{\partial r}+\frac{\partial u_{z}}{\partial z}=0 \\
& u_{r} \frac{\partial u_{r}}{\partial r}-\frac{u_{\theta}^{2}}{r}=-\frac{1}{\rho} \frac{\partial p}{\partial r}+v\left(\frac{\partial^{2} u_{r}}{\partial r^{2}}+\frac{1}{r} \frac{\partial u_{r}}{\partial r}-\frac{u_{r}}{r^{2}}\right) \\
& u_{r} \frac{\partial u_{\theta}}{\partial r}+\frac{u_{r} u_{\theta}}{r}=v\left(\frac{\partial^{2} u_{\theta}}{\partial r^{2}}+\frac{1}{r} \frac{\partial u_{\theta}}{\partial r}-\frac{u_{\theta}}{r^{2}}\right) \\
& u_{r} \frac{\partial u_{z}}{\partial r}+u_{z} \frac{\partial u_{z}}{\partial z}=-\frac{1}{\rho} \frac{\partial p}{\partial z}-g+v\left(\frac{\partial^{2} u_{z}}{\partial r^{2}}+\frac{1}{r} \frac{\partial u_{z}}{\partial r}+\frac{\partial^{2} u_{z}}{\partial z^{2}}\right)
\end{aligned}
$$

ただし, $r, \theta, z$ は渦中心軸に対して半径方向, 周方向, 軸方向の座標である. また, $u$ は流速（添え字 $r, \theta, z$ はそ れぞれの方向の成分を表す）であり，周方向および半径方向流速は軸方向に変化しないと仮定している，p は圧 力, $\rho$ は流体密度, 慩動粘性係数, $g$ は重力加速度を表す. ここで, 半径方向に一様な軸方向流速 $u_{z}=\alpha z （ \alpha$ は 軸方向流速勾配）を仮定すると, Burgers 渦モデルが得られる.

$$
\begin{aligned}
& u_{r}(r)=-\frac{1}{2} \alpha r \\
& u_{\theta}(r)=\frac{\Gamma_{\infty}}{2 \pi r}\left\{1-\exp \left(-\frac{r^{2}}{r_{0}^{2}}\right)\right\} \\
& u_{z}(z)=\alpha\left(z-z_{0}\right)
\end{aligned}
$$

ただし， $\Gamma_{\infty}$ は自由渦領域（渦中心軸から十分に離れた領域）における循環， $\mathrm{z}_{0}$ は $\mathrm{z}$ 方向の基準位置（軸方向流速 が 0 となる位置) である．また， $r_{0}$ は特性半径であり，以下の式で計算される.

$$
r_{0}=2 \sqrt{v_{e} / \alpha}
$$

ただし， $v_{e}$ は実効粘性（分子粘性と乱流渦粘性の和）である(Ito, et al., 2012). 
自由界面におけるガス巻込みの評価を行う場合, 重力, 遠心力および表面張力の力学的釣合いを表す以下の式 に基づいてガスコア長（液面窪み深さ）の算出を行う(Andersen, et al., 2003).

$$
g \frac{d h}{d r}=\frac{u_{\theta}^{2}}{r}-\frac{\sigma}{\rho} \frac{d \kappa}{d r}
$$

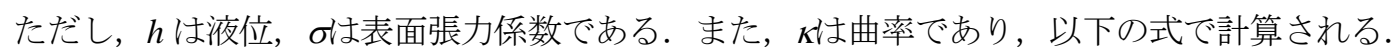

$$
\kappa(r)=\frac{h^{\prime}}{r\left\{1+\left(h^{\prime}\right)^{2}\right\}^{1 / 2}}+\frac{h^{\prime \prime}}{\left\{1+\left(h^{\prime}\right)^{2}\right\}^{3 / 2}}
$$

ただし， $h^{\prime}=d h / d r, h^{\prime \prime}=d^{2} h / d r^{2}$ である. 式（9）に式（6）及び（10）を代入して $r$ で積分することにより，界面形 状が以下の式で表される.

$$
h(r)=h_{\infty}-\frac{1}{g} \int_{r}^{\infty} \frac{u_{\theta}^{2}}{r} d r+\frac{\sigma}{\rho g} \kappa
$$

このとき，ガスコア長さ $L_{g c}$ は,

$$
L_{g c}=h_{\infty}-h(0)=\frac{\ln 2}{g}\left(\frac{\Gamma_{\infty}}{2 \pi r_{0}}\right)^{2}-\frac{4 \sigma c_{2}}{\rho g r_{0}}
$$

と計算される(Ito, et al., 2010). 上式において, 右辺第 2 項が表面張力の効果を現しており， $c_{2}$ は以下の 3 次方程 式の実数解である.

$$
c_{2}=\frac{1}{2} F r^{2}-16 \frac{F r^{2}}{W e^{2}} c_{2}^{3}
$$

ただし, Froude 数および Weber 数は以下の通り定義する.

$$
\operatorname{Fr} \equiv \frac{\Gamma_{\infty} / 2 \pi r_{0}}{\sqrt{g r_{0}}}, \quad W e \equiv \frac{\Gamma_{\infty}}{2 \pi} \sqrt{\frac{\rho}{r_{0} \sigma}}
$$

\section{3. 渦中心軸方向流速の分布を有する渦モデル}


Bohling らが提案した軸方向流速モデルは, 以下に示寸式で表される通り, 連続的な軸方向流速の分布を有して いる.

$$
u_{z}(r, z)=\frac{\gamma \beta^{2}}{\left(r^{2}+\beta^{2}\right)^{2}}\left(z-z_{0}\right)
$$

ここで, $\beta$ は渦中心領域の大きさ (半径) を決定するパラメータ, ね境界条件から決まるパラメータである. Bohling らの渦モデルでは渦中心において軸方向流速が最大となるが，実際に観察される渦においては，渦中心軸近傍に 染料コアと呼ばれる低流速流域が存在し, 渦中心では軸方向流速がほぼ 0 となることが知られている.このため, 本研究では, 渦中心において 0 となる軸方向流速の分布を表すため, Bohling らの渦モデルを一般化した以下の渦 モデルを用いる.

$$
u_{z}(r, z)=\sum_{k=1}^{n} \frac{\gamma_{k} \beta_{k}^{\xi_{k}+1}\left(\xi_{k}+1\right) r^{\xi_{k}-1}}{\left(r^{\xi_{k}+1}+\beta_{k}^{\xi_{k}+1}\right)^{2}}\left(z-z_{0}\right)
$$

ただし, 本式は $n$ 項の和からなっており, 各項 $(k, k=1, \cdots, n)$ において, $\beta_{k}$ は渦中心領域の大きさ (半径) を決 定するパラメータ， $\gamma_{k}$ は境界条件から決まるパラメータ， $\xi_{k}$ は流速分布関数の形状を決めるパラメータである. また，渦中心において軸方向流速が 0 となるため， $\xi_{k}>1$ である. 式（16）を式（1）に代入すると，半径方向流 速の分布は, 以下の通り与えられる。

$$
u_{r}(r)=-\sum_{k=1}^{n} \frac{\gamma_{k} r^{\xi_{k}}}{r^{\xi_{k}+1}+\beta_{k}^{\xi_{k}+1}}
$$

また，軸方向渦度と周方向流速の関係は，

$$
\omega_{z}(r)=\frac{1}{r} \frac{\partial r u_{\theta}}{\partial r}
$$

と記述できるため, この式を式（3）に代入することで, 軸方向渦度の式が得られる.

$$
u_{r} \omega_{z}=v \frac{\partial \omega_{z}}{\partial r}
$$

この式から, 以下の通り軸方向渦度が計算される.

$$
\omega_{z}(r)=C \prod_{k=1}^{n}\left(r^{\xi_{k}+1}+\beta_{k}^{\xi_{k}+1}\right)^{-\frac{\gamma_{k}}{\left(\xi_{k}+1\right) v}}
$$




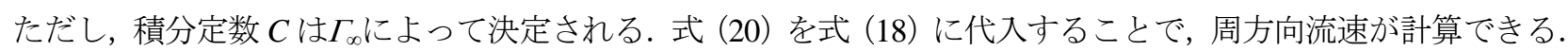

$$
u_{\theta}(r)=\frac{\Gamma_{\infty}}{2 \pi r}-\frac{1}{r} \int_{r}^{\infty} r \omega_{z} d r
$$

この式を式（9）に代入することで，界面形状およびガスコア長さが計算できる.

本モデルを用いて渦流れの評価を行う場合, (実験結果等を用いて) 実現象に即した軸方向流速の分布を仮定し, その分布に合うように式（16）中のパラメータ $\left(\beta_{k}, \gamma_{k}, \xi_{k}\right)$ を設定して計算を行う.

\section{4. 渦モデルの検証}

\section{$4 \cdot 1$ ガスコア長さの評価}

新たに開発した渦モデルの検証として，基礎的な渦実験(守屋，1998)において観察されたガスコア長さの評価

（Burgers 渦モデルおよび実験值との比較）を行う. 対象とする渦実験は，円筒容器内に形成される準定常渦の観 察を行っており, 軸方向流速の分布および界面形状が正確に計測されている. 本実験において, 容器径は $0.40 \mathrm{~m}$, 容器底面に接続された排出管の径は $0.05 \mathrm{~m}$, 容器底面からの液位 $0.50 \mathrm{~m}$, 流入流量 $8.33 \times 10^{-4} \mathrm{~m}^{3} / \mathrm{s}$ (容器壁面位 置における半径方向流速-1.33 $\times 10^{-3} \mathrm{~m} / \mathrm{s}$ ) であり，作動流体は常温の水である.

図 1 に, 液深 $0.35 \mathrm{~m}$ において計測された軸方向流速の分布を示寸（丸プロット）. 円筒容器底面には排出管が 接続されており，その近傍では縮流が生じているが，計測位置は排出管から十分に離れているため, 計測された 軸方向流速に対寸る排出管の影響は小さい，一般的な渦の軸方向流速は，渦中心においてほぼ 0 (染料コア), 渦 中心から少し離れた位置で極大值をとり，そこから半径方向に減少していき渦中心から十分離れた領域で 0 に漸 近する. 式（16）において $n=1$ とした場合, 渦中心近傍の挙動を再現するためには比較的小さな值の $\beta$ と比較的 大きな值の $\xi か ゙$ 必要である (図 1 中の点線参照) が, そのような関数は $r$ 増加とともに急激に減少するため, 渦 中心から離れた領域における下降流速分布を正確に表すことはできない. ここでは, $n=2$ とし, 渦中心近傍での 分布を表す関数（図 1 中の破線; $\beta_{1}=1.10 \times 10^{-2} \mathrm{~m}, \gamma_{1}=2.22 \times 10^{-5} \mathrm{~m}, \xi_{1}=2.5$ ）および渦中心から離れた領域にお ける分布を表す関数（図 1 中の点線; $\beta_{2}=0.10 \mathrm{~m}, \gamma_{2}=2.96 \times 10^{-4} \mathrm{~m}, \xi_{2}=1.2$ ）の組合せによって計測された軸方 向流速の分布を模擬する (図 1 中の実線)。その際，式（17）において $r=0.20 \mathrm{~m}$ (容器壁面位置）の半径方向流 速が-1.33 × $10^{-3} \mathrm{~m} / \mathrm{s}$ になることも考慮している.

開発した渦モデル (Axial velocity distribution モデル) および Burgers 渦モデルによって評価された流速分布を, 図 2 に示す.ただし, 周方向流速を計算する際には, 実験において得られた循環 $\left(\Gamma_{\infty}=4.42 \times 10^{-2} \mathrm{~m}^{2} / \mathrm{s}\right)$ を用いて 積分定数を決定している. また, Burgers モデルによる評価においては, 境界条件 $\left(r=0.20 \mathrm{~m}\right.$ において $u_{r}=-1.33 \times$ $\left.10^{-3} \mathrm{~m} / \mathrm{s}\right)$ から水平断面平均の軸方向流速勾配（ $\alpha=1.33 \times 10^{-2} 1 / \mathrm{s} ）$ を求め, 式（7）によって（一様な）軸方向流 速を計算する. Axial velocity distribution モデルによって計算された流速分布は実験結果と良く一致しており, Axial velocity distribution モデルが渦の流速分布を再現できていることが分かる. 一方, Burgers モデルによって評価し た流速分布は実験值との乘離が大きく, 一様な軸方向流速の仮定では渦の流速分布を正しく表せないことが分か る. すなわち，渦の流速分布を正しくモデル化するためには，渦中心近傍における軸方向流速の分布を考慮する 必要がある。

図 3 に, 式（9）によって計算された界面形状を示す. Axial velocity distribution モデルによる評価結果は実験結 果と良く一致しているが，Burgers モデルによる評価結果は界面変形を過小評価している．実際，ガスコア長は， 実験值の $0.11 \mathrm{~m}$ に対して, Axial velocity distribution モデルが $0.12 \mathrm{~m}$, Burgers モデルが $0.011 \mathrm{~m}$ となっている. 


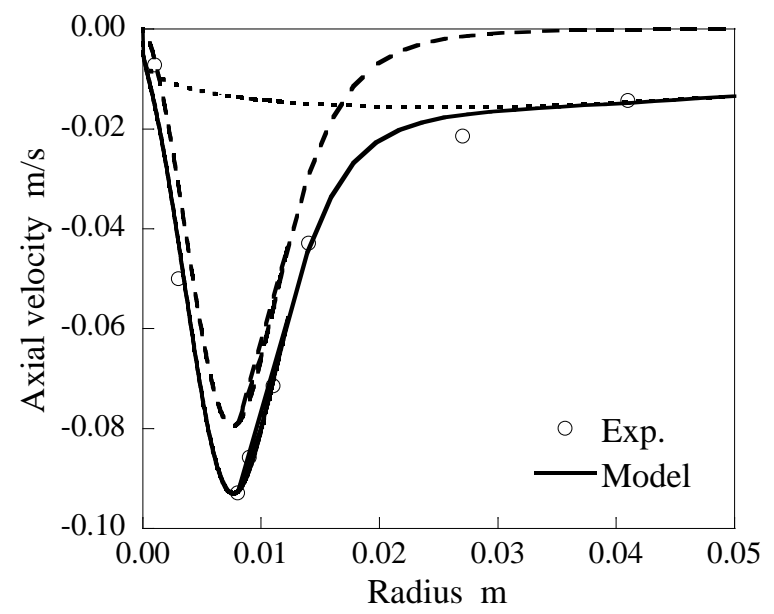

Fig. 1 Axial velocity distributions of the experimental data (open circles) and the new vortex model (solid line). The axial velocity of the vortex model consists of two terms $\left(n=2\right.$ in Eq. 16) and the first term $\left(\beta_{1}=1.10 \times 10^{-2} \mathrm{~m}, \gamma_{1}=2.22 \times\right.$ $\left.10^{-5} \mathrm{~m}, \quad \xi_{1}=2.5\right)$ and the second term $\left(\beta_{2}=0.10 \mathrm{~m}, \quad \gamma_{2}=2.96 \times 10^{-4} \mathrm{~m}, \xi_{2}=1.2\right)$ are shown by the dashed and the dotted lines, respectively.

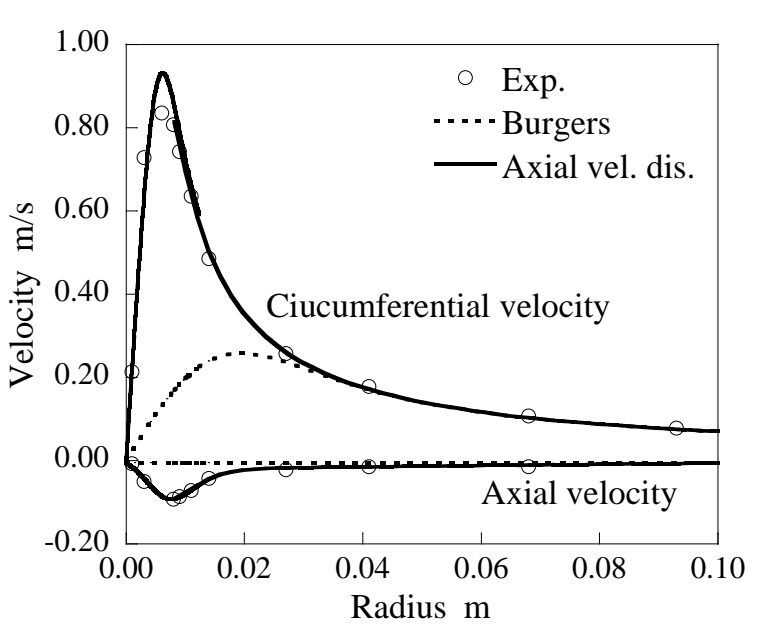

Fig. 2 Circumferential and axial velocity distributions of the experimental data (open circles), the Burgers model (dotted lines) and the axial velocity distribution model (solid lines).

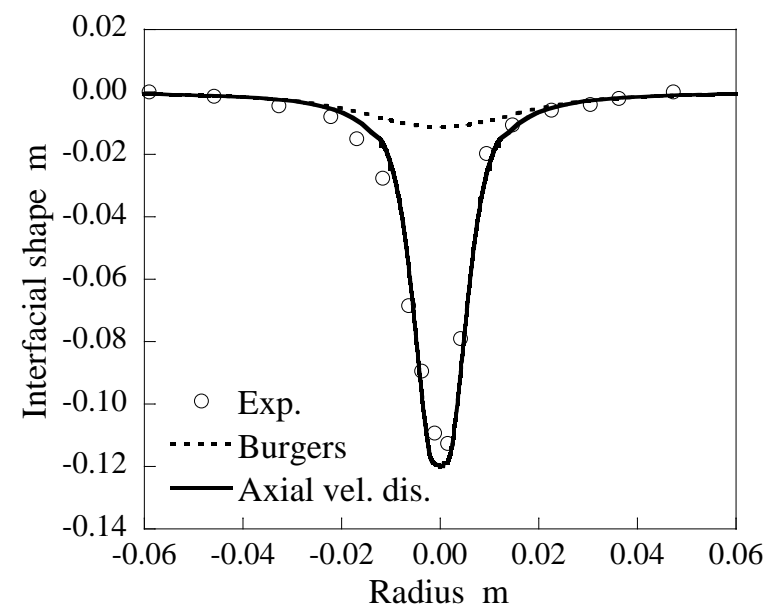

Fig. 3 Interfacial shapes of the experimental data (open circles), the Burgers model (dotted line) and the axial velocity distribution model (solid line).

\section{$4 \cdot 2$ 界面変形の影響評価}

Andersen らは, 式（1）の代わりに，界面変形を考慮した以下の連続式を提案している(Andersen, et al., 2006).

$$
\frac{1}{r} \frac{\partial(h-z) r u_{r}}{\partial r}=u_{z}(r, z)
$$

この式は，界面の変形が軸方向流速勾配に与える影響を表している.

図 4 に, Axial velocity distribution モデルによって計算された半径方向流速分布と界面形状を式（22）に代入し て計算した軸方向流速分布と元の軸方向流速分布（式（16））の比較を示す. 式（22）から得られた分布の方が軸 方向流速の極大值が大きく，また，極大值をとる半径もやや大きくとなっている．しかし，両者に大きな差は無 いため, 界面変形の影響は限定的であると考えられる. 寸なわち, Axial velocity distribution モデルを用いた評価 により，渦の流速分布，界面形状を正確に表寸ことが可能である. 


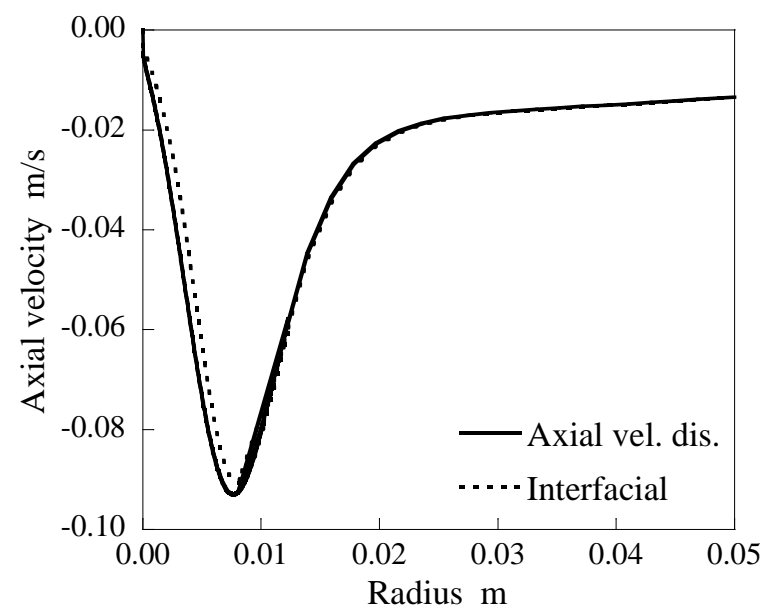

Fig. 4 Comparison of the axial velocity distributions with and without considering the influence of the interfacial deformation. The dotted line is calculated by employing Eq. 22, instead of Eq. 1, to consider the influence of the interfacial deformation.

\section{$4 \cdot 3$ 従来手法の妥当性評価}

本研究において新たに開発した渦モデルは，高い現象再現性を有するが，周方向流速や界面形状の計算負荷が 大きい. 一方, Burgers 渦モデル等の比較的単純な渦モデルを用いる場合, 計算負荷は大幅に削減できる.ただし, 4.1 節で示した通り，遠方場の境界条件に基づいて Burgers モデルによる評価を行う場合，周方向流速およびガス コア長さを大幅に過小評価することになる，そこで，著者らの渦評価手法においては，遠方境界に基づく軸方向 流速勾配ではなく, CFD 結果に基づいて渦中心近傍（第二不変量が負となる領域）で平均化した局所の軸方向流 速勾配を用いて評価を行っている. 寸なわち, 軸方向流速勾配 $\alpha$ は, 第二不変量が 0 となる点を結んだ閉曲線 $C C$ に沿って速度 $\vec{u}$ 積分することで計算される.

$$
\alpha=\frac{\int_{C C} \vec{u} \cdot \vec{n}_{C C}|d \vec{s}|}{A}
$$

ただし， $\vec{n}_{C C}$ およびd $\vec{s}$ は，閉曲線 $C C$ 上の外向き単位法線ベクトルおよび単位接線ベクトルであり，A は $C C$ に よって囲まれる領域の面積である.

式 (23) を用いて洞中心近傍の領域における実効的な軸方向流速に基づいて計算を行うモデル（Modified Burgers 渦モデル）の妥当性を確認するため，4.1 節と同じ基礎的な渦実験を対象とした評価を行う. Axial velocity distribution モデルによって得られた流速分布が実現象を再現していると仮定し，その流速場に基づいて式（23） から評価した軸方向流速勾配は 0.17 1/s となり,オリジナルの Burgers 渦モデルによる計算結果 $\left(\alpha=1.33 \times 10^{-2} 1 / \mathrm{s}\right)$ の約 13 倍となっている.このため, 図 5 に示寸通り, 渦中心付近の第二不変量が負となる領域において, 大きな 軸方向流速が得られる. それに応じて, 図6に示寸通り, Modified Burgers 渦モデルではガスコア長さが $0.14 \mathrm{~m}$ と計算され，実駼結果および渦中心軸方向流速の分布を有する渦モデルによる計算結果を過大評価するものの， オリジナルの Burgers 渦モデルによる結果と比較すると評価精度が著しく向上している．したがって，非常に高 い計算精度が要求されるケースでは，本論文において新たに開発した渦モデルなどを用いて計算を行う必要があ るが，それ以外のケース（設計評価等において数 $10 \%$ 程度の計算誤差が許容されるケース）では，渦中心近傍で 平均化した実効的な軸方向流速を用いる Modified Burgers 渦モデルによる計算を行うことが可能であると考える. 


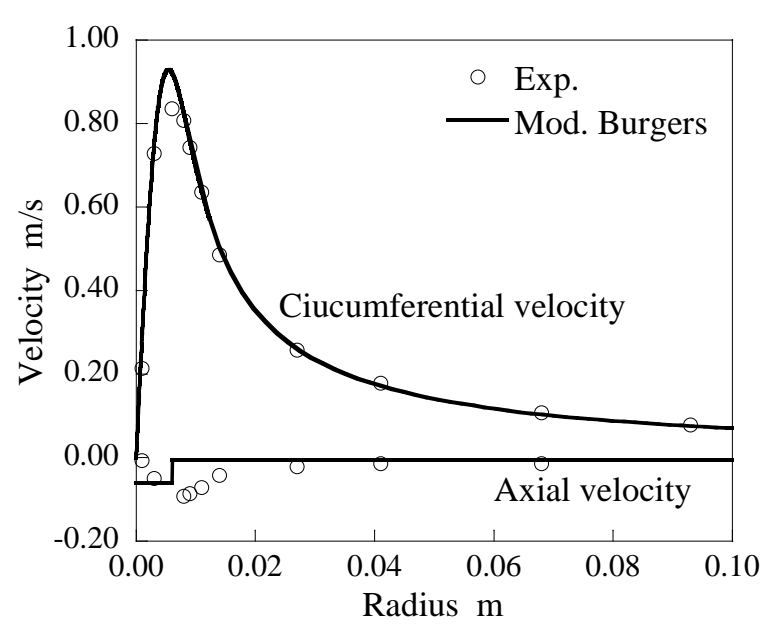

Fig. 5 Circumferential and axial velocity distributions of the experimental data (open circles) and the modified Burgers model (solid lines).

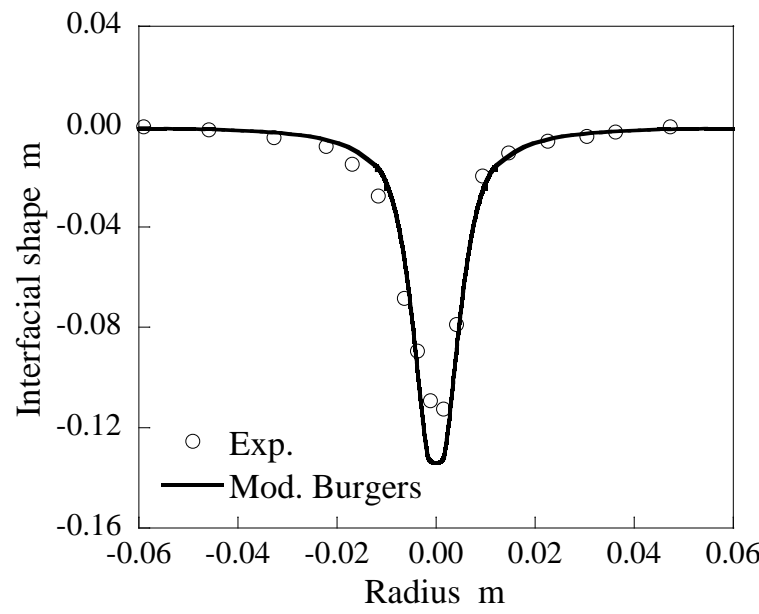

Fig. 6 Interfacial shapes of the experimental data (open circles) and the modified Burgers model (solid line).

\section{5. 結 言}

本研究では，軸方向流速の半径方向分布を考慮した渦モデルを新たに開発・検証し，実験において計測された 渦の流速分布，自由界面形状を再現できることを示した．また，渦中心近傍で平均化した実効的な軸方向流速を 用いた Burgers 渦モデルに基づく計算は，低負荷で妥当な結果を与えることを確認した.

\section{文献}

Andersen, A., Bohr, T., Stenum, B., Juul Rasmussen, J. and Lautrup, B., Anatomy of a bathtub vortex, Physical Review Letters, Vol. 91, No. 10 (2003).

Andersen, A., Bohr, T., Stenum, B., Juul Rasmussen, J. and Lautrup, B., The bathtub vortex in a rotating container, Journal of Fluid Mechanics, Vol. 556 (2006), pp. 121-146.

Bohling, L., Andersen, A. and Fabre, D., Structure of a steady drain-hole vortex in a viscous fluid, Journal of Fluid Mechanics, Vol. 656 (2010), pp. 177-188.

Burgers, J. M., A mathematical model illustrating the theory of turbulence, Advance in applied mechanics (edited by Mises, R. and Karman, T.), Academic Press ING., New York (1948).

Einstein, H. A. and Li, H., Steady vortex flow in a real fluid, Proceedings of heat transfer and Fluid Mechanics Institute, Stanford University (1951), pp. 33-43.

Ito, K., Eguchi, Y., Monji, H., Ohshima, H., Uchibori, A. and Xu, Y., Improvement of gas entrainment evaluation method -introduction of surface tension effect-, Journal of Nuclear Science and Technology, Vol. 47 (2010), pp. 771-778.

Ito, K., Ohshima, H. and Imai, Y., Study on turbulent modeling in gas entrainment evaluation method, Journal of Power and Energy System, Vol. 6, No. 2 (2012), pp. 151-164.

守屋祥一, 伸長渦理論と詳細可視化·計測に基づく自由表面渦の流動特性評価, 電力中央研究所報告書 U97072 (1998).

大島宏之, 田中伸厚, 江口譲, 西村元彦, 功刀資彰, 内堀昭寛, 伊藤啓, 堺公明, 高速炉におけるガス巻込み現象の 防止基準，(I) 数值解析によるガス巻込み現象再現精度の検証, 日本原子力学会和文論文誌, Vol. 11, No. 4 (2012a), pp. 316-328.

大島宏之, 江口譲, 功刀資彰, 上出英樹, 堺公明, 伊藤啓, 高速炉におけるガス巻込み現象の防止基準, (II) ガス巻 込久発生判定手法の提案, 日本原子力学会和文論文誌, Vol. 11, No. 4 (2012b), pp. 329-339.

Sullivan, R. D., A two-cell solution of the Navier-Stokes equations, Journal of Aerospace Sciences, Vol. 26 (1959), pp. 767-768.

\section{References}


Andersen, A., Bohr, T., Stenum, B., Juul Rasmussen, J. and Lautrup, B., Anatomy of a bathtub vortex, Physical Review Letters, Vol. 91, No. 10 (2003).

Andersen, A., Bohr, T., Stenum, B., Juul Rasmussen, J. and Lautrup, B., The bathtub vortex in a rotating container, Journal of Fluid Mechanics, Vol. 556 (2006), pp. 121-146.

Bohling, L., Andersen, A. and Fabre, D., Structure of a steady drain-hole vortex in a viscous fluid, Journal of Fluid Mechanics, Vol. 656 (2010), pp. 177-188.

Burgers, J. M., A mathematical model illustrating the theory of turbulence, Advance in applied mechanics (edited by Mises, R. and Karman, T.), Academic Press ING., New York (1948).

Einstein, H. A. and Li, H., Steady vortex flow in a real fluid, Proceedings of heat transfer and Fluid Mechanics Institute, Stanford University (1951), pp. 33-43.

Ito, K., Eguchi, Y., Monji, H., Ohshima, H., Uchibori, A. and Xu, Y., Improvement of gas entrainment evaluation method -introduction of surface tension effect-, Journal of Nuclear Science and Technology, Vol. 47 (2010), pp. 771-778.

Ito, K., Ohshima, H. and Imai, Y., Study on turbulent modeling in gas entrainment evaluation method, Journal of Power and Energy System, Vol. 6, No. 2 (2012), pp. 151-164.

Moriya, S, Estimation of hydraulic characteristics of free surface vortices on the basis on extension vortex theory and fine model test measurements, Technical Reports of Central Research Institute of Electric Power Industry, U97072 (1998) (in Japanese).

Ohshima, H., Tanaka, N.,Eguchi, Y., Nishimura, M., Kunugi, T., Uchibori, A., Ito, K. and Sakai, T., Standard for prevention of gas entrainment phenomena in fast reactors (I) validations of CFD methods for reproducibilities of gas entrainment phenomena, Transactions of the Atomic Energy Society of Japan, Vol. 11, No. 4 (2012a), pp. 316-328 (in Japanese).

Ohshima, H., Eguchi, Y., Kunugi, T., Kamide, H., Sakai, T. and Ito, K., Standard for prevention of gas entrainment phenomena in fast reactors (II) Proposal of Gas Entrainment Evaluation Method, Transactions of the Atomic Energy Society of Japan, Vol. 11, No. 4 (2012b), pp. 329-339 (in Japanese).

Sullivan, R. D., A two-cell solution of the Navier-Stokes equations, Journal of Aerospace Sciences, Vol. 26 (1959), pp. 767-768. 